University of Nebraska - Lincoln

DigitalCommons@University of Nebraska - Lincoln

\title{
The association between depression and anxiety and use of oral health services and tooth loss
}

\author{
Catherine A. Okoro \\ Centers for Disease Control and Prevention, COkoro@cdc.gov \\ Tara W. Strine \\ Centers for Disease Control and Prevention, tws2@cdc.gov \\ Paul I. Eke \\ Centers for Disease Control and Prevention, peke@cdc.gov \\ Satvinder S. Dhingra \\ Centers for Disease Control and Prevention, evc7@cdc.gov \\ Lina S. Balluz \\ Centers for Disease Control and Prevention, Iballuz@cdc.gov
}

Follow this and additional works at: https://digitalcommons.unl.edu/publichealthresources

Part of the Public Health Commons

Okoro, Catherine A.; Strine, Tara W.; Eke, Paul I.; Dhingra, Satvinder S.; and Balluz, Lina S., "The association between depression and anxiety and use of oral health services and tooth loss" (2012). Public Health Resources. 264.

https://digitalcommons.unl.edu/publichealthresources/264

This Article is brought to you for free and open access by the Public Health Resources at DigitalCommons@University of Nebraska - Lincoln. It has been accepted for inclusion in Public Health Resources by an authorized administrator of DigitalCommons@University of Nebraska - Lincoln. 


\section{The association between depression and anxiety and use of oral health services and tooth} loss

Okoro CA, Strine TW, Eke PI, Dhingra SS, Balluz LS. The association between depression and anxiety and use of oral health services and tooth loss. Community Dent Oral Epidemiol 2012; 40: 134-144. ㅇ 2011 John Wiley \& Sons A/S

Abstract - Objective: The purpose of this study is to examine the associations among depression, anxiety, use of oral health services, and tooth loss. Methods: Data were analysed for 80486 noninstitutionalized adults in 16 states who participated in the 2008 Behavioral Risk Factor Surveillance System. Binomial and multinomial logistic regression analyses were used to estimate predicted marginals, adjusted prevalence ratios, adjusted odds ratios (AOR) and their 95\% confidence intervals (CI). Results: The unadjusted prevalence for use of oral health services in the past year was 73.1\% [standard error (SE), 0.3\%]. The unadjusted prevalence by level of tooth loss was $56.1 \%$ (SE, $0.4 \%$ ) for no tooth loss, $29.6 \%$ (SE, $0.3 \%$ ) for 1-5 missing teeth, 9.7\% (SE, 0.2\%) for 6-31 missing teeth and $4.6 \%$ (SE, $0.1 \%$ ) for total tooth loss. Adults with current depression had a significantly higher prevalence of nonuse of oral health services in the past year than those without this disorder $(P<0.001)$, after adjustment for age, sex, race/ethnicity, education, marital status, employment status, adverse health behaviours, chronic conditions, body mass index, assistive technology use and perceived social support. In logistic regression analyses employing tooth loss as a dichotomous outcome ( 0 versus $\geq 1)$ and as a nominal outcome ( 0 versus $1-5,6-31$, or all), adults with depression and anxiety were more likely to have tooth loss. Adults with current depression, lifetime diagnosed depression and lifetime diagnosed anxiety were significantly more likely to have had at least one tooth removed than those without each of these disorders $(P<0.001$ for all), after fully adjusting for evaluated confounders (including use of oral health services). The adjusted odds of being in the 1-5 teeth removed, 6-31 teeth removed, or all teeth removed categories versus 0 teeth removed category were increased for adults with current depression versus those without $(\mathrm{AOR}=1.35 ; 95 \% \mathrm{CI}=1.14-1.59$; $\mathrm{AOR}=1.83 ; 95 \%$ $\mathrm{CI}=1.51-2.22 ;$ and $\mathrm{AOR}=1.44 ; 95 \% \mathrm{CI}=1.11-1.86$, respectively). The adjusted odds of being in the 1-5 teeth removed and 6-31 teeth removed categories versus 0 teeth removed category were also increased for adults with lifetime diagnosed depression or anxiety versus those without each of these disorders. Conclusion: Use of oral health services and tooth loss was associated with depression and anxiety after controlling for multiple confounders.
Catherine A. Okoro ${ }^{1}$, Tara W. Strine ${ }^{1}$, Paul I. Eke ${ }^{2}$, Satvinder S. Dhingra ${ }^{1}$ and Lina S. Balluz ${ }^{1}$

${ }^{1}$ Division of Behavioral Surveillance, Public Health Surveillance Program Office, Office of Surveillance, Epidemiology, and Laboratory Services, Centers for Disease Control and Prevention Atlanta, GA, USA, ${ }^{2}$ Division of Adult and Community Health, National Center for Chronic Disease Prevention and Health Promotion, Office of

Noncommunicable Diseases, Injury and Environmental Health, Centers for Disease Control and Prevention Atlanta, GA, USA.

Key words: adults; anxiety; Behavioral Risk Factor Surveillance System; depression; oral health; population based; psychiatric disorders; surveillance

Catherine A. Okoro, Division of Behavioral Surveillance, Public Health Surveillance Program Office, Office of Surveillance, Epidemiology, and Laboratory Services, Centers for Disease Control and Prevention, 1600 Clifton Road NE, MS E-97, Atlanta, GA 30333, USA

Tel.: +1 4044980504

Fax: +1 4044980585

e-mail: Cokoro@cdc.gov

Disclaimer: The findings and conclusions in this article are those of the authors and do not necessarily represent the official position of the Centers for Disease Control and

Prevention.

Submitted 13 October 2010; accepted 22 July 2011
Mental health disorders are leading causes of morbidity, disability and mortality in the United States (1). In the general, U.S. population, approximately $46 \%$ of people, will meet the criteria for a mental health disorder at some point in their lifetime, and half of all lifetime cases occur by mid-adolescence (2). Of these lifetime disorders, approximately $17 \%$ of people will have a major depressive disorder and $29 \%$ will have an anxiety disorder (2). Comparatively, the 12-month preva- 
lence of a mental health disorder is $26 \%$ ( $7 \%$ for a major depressive disorder and $18 \%$ for an anxiety disorder) (3). In the United States, mental health disorders consume substantial economic resources each year; an estimated $\$ 150$ billion annually, $\$ 71$ billion in direct costs and $\$ 79$ billion in indirect costs (4). Nevertheless, while mental health disorder severity is strongly tied to treatment, one- to two-thirds of serious disorders remain untreated each year (5).

The U.S. Surgeon General's (1) report on mental health highlighted research that showed that mental health is associated with physical health and general well-being. Studies have documented an association between mental health disorders and adverse health behaviours, chronic disease, obesity, inadequate social support and a poor health-related quality of life (6-9). Several studies have not found a lower likelihood of preventive health services use $(10,11)$ or receiving routine health care in the past 5 years (12) among persons with mental health disorders compared with those without. However, other studies have found modest associations for not seeking preventive health care screenings among persons with depressive disorders $(13,14)$.

Relatively, few studies have examined the relationship between use of oral health services and mental health disorders; and those that have, have had mixed results. Anttila et al. (15) found an association between depression and fewer dental visits among Northern Finland's 1966 Birth Cohort (i.e., 31-32 year olds), but did not have similar findings for persons with anxiety symptoms. In a Northern Finland population-based study of men and women aged 55 years, women with depressive symptoms reported a longer time since their last dental visit compared with those without depressive symptoms, while depressive symptoms in nonsmoking men were associated with edentulousness (16). Conversely, in a multivariate analysis of 388 Portuguese health science students (mean age $21 ; 75 \%$ women), students who were anxious were more likely to have visited a dentist in the past year than those who were not anxious (17).

Studies have also found an association between depression and periodontal disease, possibly because of behavioural and physiologic mechanisms (18-21). For example, Genco et al. (19) reported that psychosocial measures of stress (e.g., financial strain) that manifest as depression are significantly associated with periodontal disease, as measured by clinical attachment loss or alveolar bone loss. However, other studies have found no association between depression and periodontal disease or tooth loss or have had mixed results $(16,22)$. In addition, studies have reported an association between depressive symptoms and higher lactobacillus counts that may contribute to an increased risk for dental caries among persons with depression $(23,24)$. For example, certain characteristics associated with depression may support the growth of lactobacilli, such as diet, oral health behaviour and disorders of the endocrine and monoamine regulatory mechanisms (23). In addition, saliva assists in preventing bacterial adherence to tissues and some of these factors may adversely affect salivary secretion. Among persons being treated for depression, the use of antidepressant medication has been associated with an increased risk for dental caries as well $(15,23,25-$ 27). For example, some antidepressant medications may reduce salivary secretion and thus, encourage the growth of lactobacilli which may lead to increased dental caries (15, 23, 25-27). Other oral health-related side effects of antidepressant medications include xerostomia, dysgeusia and bruxism $(24,27)$.

Given that an estimated one in five dental patients may have a depressive disorder (24) as well as the early onset and high prevalence of these disorders, developing evidence-based primary and secondary prevention strategies are essential. The results from this study will add to the research base and inform public health professionals' and dental health professionals' decision making on effective interventions to identify and address depression and anxiety disorders during the provision of oral health care. Nonetheless, it should be noted that our study uses 2008 Behavioral Risk Factor Surveillance System (BRFSS) cross-sectional survey data to examine whether depression and anxiety and the use of oral health services and tooth loss are related; and thus, cannot determine the directionality of these relationships. Specifically, our study aims to examine whether associations exist between depression and anxiety and use of oral health services and tooth loss after taking into consideration potential confounders.

\section{Materials and methods}

The BRFSS is a state-based surveillance system that is operated by state health departments in collaboration with the U.S. Centers for Disease Control and Prevention (CDC). A detailed descrip- 
tion of the survey methods is available elsewhere (28). Briefly, the surveillance system collects data on many of the behaviours and conditions that place adults (aged $\geq 18$ years) at risk for chronic disease $(29,30)$. Trained interviewers collect data monthly by using an independent probability sample of households with telephones among the noninstitutionalized U.S. adult population. The data from each state are weighted to reflect the respondent's probability of selection and the ageand sex-specific or race/ethnicity-, age- and sexspecific population of the state. Representative state estimates are then aggregated. All BRFSS questionnaires and data are available at http:// www.cdc.gov/brfss.

In 2008, 16 states administered the optional BRFSS Anxiety and Depression Module (ADM): Arizona, Colorado, Hawaii, Idaho, Illinois, Kansas, Louisiana, Maine, Massachusetts, Mississippi, Nebraska, New York, North Dakota, Ohio, Vermont and Washington. Therefore, the analyses are limited to data from those 16 states. Based on Council of American Survey and Research Organizations (CASRO) guidelines, the median response rate for the 16 states that used the ADM was $49.9 \%$ and ranged from $40.0 \%$ in New York to $65.5 \%$ in Nebraska (31). Similar to other telephone surveys, a number of factors have impacted the BRFSS CASRO response rate: such as a decreased number of households with landline telephones - an estimated $18.9 \%$ of households had only wireless telephones in 2008 (32); increased telephone number portability; and advancements in telephone technologies (e.g., answering machines, caller ID, voicemail) (33). These factors may potentially introduce noncoverage bias. However, researchers have found that estimates derived from the BRFSS are comparable to other U.S. population surveys $(34,35)$.

The BRFSS ADM consists of 10 questions, including the Patient Health Questionnaire 8 (PHQ-8) (36). The PHQ-8 is adapted from the 9item scale (i.e. PHQ-9) $(36,37)$, which is based on nine criteria on which the Diagnostic and Statistical Manual of Mental Disorders, Fourth Edition (38) diagnosis of depressive disorders is based. The 9th criterion was omitted because it assesses suicidal or self-injurious ideation, and adequate intervention could not be conducted over the telephone. The PHQ-8 has comparable sensitivity and specificity to other depression measures and requires less time to administer $(6,36,37)$.

We used the PHQ- 8 to estimate the prevalence of current depressive symptoms. The PHQ-8 response set was standardized to be similar to other BRFSS questions by asking the number of days in the past 2 weeks the individual experienced a particular depressive symptom (Online Appendix). The modified response set was converted back to the original PHQ-8 response set: $0-1$ day $=$ 'not at all'; 2-6 days = 'several days'; 7-11 days = 'more than half the days'; and 12-14 days = 'nearly every day', with points (0-3) assigned to each category, respectively. The scores for each item were summed to produce a total score between 0 and 24 points. A total score of $0-4$ represented no significant depressive symptoms; a total score of 59 represented mild symptoms, 10-14 represented moderate symptoms, 15-19 represented moderately severe symptoms and 20-24 represented severe symptoms (36). Respondents were considered to have current depressive symptoms (i.e. past 2 weeks) if their total score was $\geq 10$, which has an $88 \%$ sensitivity and specificity for major depression $(36,37)$.

Lifetime diagnoses of a depressive or an anxiety disorder by a healthcare professional was assessed with the remaining two questions of the ADM: 'Has a doctor or other healthcare provider EVER told you that you had a depressive disorder (including depression, major depression, dysthymia or minor depression)?' and 'Has a doctor or other healthcare provider EVER told you that you had an anxiety disorder (including acute stress disorder, anxiety, generalized anxiety disorder, obsessive-compulsive disorder, panic disorder, phobia, post-traumatic stress disorder or social anxiety disorder)?'

Three questions were used to determine survey participant's use of oral health services and tooth loss. Specifically, BRFSS respondents were asked: (1) 'How long has it been since you last visited a dentist or a dental clinic for any reason?', (2) 'How many of your permanent teeth have been removed because of tooth decay or gum disease? Include teeth lost to infection, but do not include teeth lost for other reasons, such as injury or orthodontics' and (3) 'How long has it been since you had your teeth cleaned by a dentist or dental hygienist?' Instructions were given to interviewers to include wisdom tooth loss because of tooth decay or gum disease (i.e. infection). Predefined tooth loss response categories were as follows: none, 1-5, 6 or more but not all, and all. Respondents who reported never having visited a dentist or having all their permanent teeth removed were not asked how long it had been since they had their teeth 
cleaned by a dentist or dental hygienist. Based on these questions, receipt of oral health services (i.e. dental visit or cleaning visit or both $<1$ year ago versus 1 or more years ago or never) and tooth loss were assessed.

The demographic variables in our analyses included respondents' age (18-34, 35-44, 45-54, 55-64, 65-74 and 275), sex, race/ethnicity (nonHispanic white, non-Hispanic black, Hispanic and other), education (less than high school diploma, high school graduate or GED, some college and college graduate), employment (employed, unemployed, homemaker or student, retired and unable to work) and marital status (married, divorced or separated, widowed and never married or member of an unmarried couple). In addition to demographics, five chronic health conditions, including angina pectoris, myocardial infarction, stroke, diabetes and asthma were assessed by asking respondents whether they had ever been told by a doctor or other health professional that they had these conditions.

All respondents were asked their height and weight and about their cigarette smoking habits, alcohol consumption, use of assistive technology and perceived level of social and emotional support. Respondents' body mass index $[\mathrm{BMI}=$ weight in kilograms $(\mathrm{kg})$ divided by the square of height in meters $\left(\mathrm{m}^{2}\right)$ ] was determined from selfreported height and weight. Respondents were classified as underweight $(<18.5)$, normal weight $(18.5$ to $<25)$, overweight $(25$ to $<30)$ and obese $(\geq 30)$. Respondents' cigarette smoking status was determined by two questions: (1) 'Have you smoked at least 100 cigarettes in your entire life?' and (2) 'Do you now smoke cigarettes every day, some days, or not at all?' Based on their responses, respondents were placed in one of four categories. Respondents who reported that they had not smoked 100 cigarettes in their lifetimes were defined as 'never smokers'. Those who responded in the affirmative for having smoked 100 cigarettes in their lifetimes and who also said that they do not smoke at all now were defined as 'former smokers'. Respondents who reported ever smoking 100 cigarettes and responded that they now smoke some days or every day were classified as 'current smokers'. Heavy drinkers were defined as men who reported drinking more than two drinks per day and as women who reported drinking more than one drink per day (39). Respondents' use of assistive technology was based on the question: 'Do you now have any health problem that requires you to use special equipment, such as a cane, a wheelchair, a special bed, or a special telephone?' Perceived level of social support was assessed with the question, 'How often do you get the social and emotional support that you need?' Possible responses were grouped into three categories: (i) always or usually, (ii) sometimes and (iii) rarely or never.

\section{Statistical analyses}

We used SAS and SAS-callable SUDAAN in all analyses to account for the complex survey design $(40,41)$. Crude (unadjusted) prevalence estimates, adjusted predicted marginals and adjusted prevalence ratios (APRs) and 95\% confidence intervals (CIs) were obtained using the MULTILOG procedure in SUDAAN (41). Specifically, we used binomial logistic regression analysis to estimate predicted marginals and APRs for each outcome variable [i.e. use of oral health services (dental and/or cleaning visit in the past year versus $\geq 1$ years ago or never) and tooth loss (none versus $\geq 1$ teeth removed)] in association with each independent variable (i.e. current depression, lifetime diagnosed depression and lifetime diagnosed anxiety; referent $=$ absence of disorder) after adjustment for multiple confounders. We used multinomial logistic regression analysis to estimate adjusted odd ratios (AORs) for tooth loss [i.e. 0 (the referent group), 1-5, 6-31, and all] in association with each independent variable, and to estimate predicted marginals and APRs by level of tooth loss (i.e. 0, 1-5, 6-31 and all) in association with each independent variable. We tested the proportional odds assumption of cumulative logit using the SURVEYLOGISTIC procedure in SAS (40). The proportional odds assumption was invalid for our models (i.e. Score tests: $P<0.001$ ); therefore, multinomial logistic regression analysis rather than ordinal logistic regression analysis was used. For each outcome of interest, we tested interactions between sex and age group with each independent variable and found them to be nonsignificant with one exception - for tooth loss, the interaction term for lifetime diagnosed depression and age group had borderline significance $(P=0.0525)$. For all analyses, $P$ values $<0.05$ were considered significant. Eight states - Colorado, Kansas, Maine, Massachusetts, Nebraska, New York, Ohio and Washington - collected the ADM on a subset of their respective state's sample. Information on the weighting methodology and the weights to use for each of these states can be found at http:// 
www.cdc.gov/brfss/technical_infodata/surveydata/2008/2008_multiple.htm.

\section{Results}

Of the total 96223 respondents, we excluded those with unknown status for receipt of oral health services and tooth loss $(n=2129)$, those with unknown status for depression and anxiety ( $n=11028)$ and those with missing data on demographics $(n=2580)$. Respondents excluded from the study population were more likely than those included to be aged 65 years or older, nonwhite, not currently married, not currently employed and not to have higher than a high school education $(P<0.0001$ for all). There was no difference in study inclusion by sex $(P=0.5545)$. Table 1 presents the characteristics of the final analytic sample $(n=80486)$. Among the respondents included in our analyses, $8.1 \%$ [standard error (SE), 0.2\%] had current depression, $16.0 \%$ (SE, $0.3 \%$ ) had a lifetime diagnosis of depression and $12.3 \%$ (SE, $0.2 \%$ ) had a lifetime diagnosis of anxiety.

\section{Use of oral health services}

Overall, 73.1\% (SE, 0.3\%) of adults used oral health services in the past year. Among adults, the unadjusted prevalence of nonuse of oral health services in the past year was significantly higher among those with current depression, lifetime diagnosed depression and lifetime diagnosed anxiety than those without each disorder, respectively $(P<0.001$ for all) (Table 2$)$. After adjustment for sociodemographic characteristics (age, sex, race/ethnicity, education, marital status and employment status), adults with current depression and lifetime diagnosed depression were $1.38(95 \% \quad \mathrm{CI}=1.28-1.49)$ and $1.15(95 \%$ $\mathrm{CI}=1.08-1.22)$ times as likely not to have had a dental or cleaning visit in the past year than those without each of these disorders (Table 2, Model 1). After further adjustment for adverse health behaviours, comorbid conditions, BMI, and use of assistive technology, the association between nonuse of oral health services and current depression remained significant; however, for adults with lifetime diagnosed depression, the association attenuated and was no longer significant (Table 2, Model 2). After further adjustment for perceived social support, adults with current depression remained significantly more likely to have not used oral health services in the past year (Table 2, Model 3).

\section{Tooth loss as a dichotomous outcome}

Overall, $56.1 \%$ (SE, $0.4 \%$ ) of adults had no tooth loss, $29.6 \%$ (SE, $0.3 \%$ ) had 1-5 missing teeth, 9.7\% (SE, 0.2\%) had 6-31 missing teeth and 4.6\% (SE, $0.1 \%$ ) had total tooth loss. The unadjusted prevalence of having at least one tooth removed differed significantly by current depression status, lifetime diagnosed depression and lifetime diagnosed anxiety $(P<0.001$ for all) (Table 3$)$. Among adults, after adjustment for sociodemographic characteristics and use of oral health services, those with current depression, lifetime diagnosed depression and lifetime diagnosed anxiety were significantly more likely to have had at least one tooth removed than those without each of these disorders (Table 3, Model 1). After fully adjusting for all evaluated confounders, these associations remained significant (Table 3, Model 3).

\section{Tooth loss as a nominal outcome}

Table 4 presents the unadjusted and AORs of the multinomial logistic regression analysis for depression and anxiety by level of tooth loss. Among adults, the unadjusted results indicate that each of these conditions were associated with an increased likelihood of tooth removal compared with no tooth removal. After adjusting for sociodemographic characteristics and use of oral health services, the estimated odds of being in the 6-31 teeth removed versus 0 teeth removed categories was almost tripled (AOR $=2.89$; 95\% CI $=2.43-$ 3.44) for those with current depression versus those without (Table 4, Model 1). The estimated odds of being in the 1-5 teeth removed or all teeth removed categories versus 0 teeth removed category were significantly increased as well for those with current depression versus those without. After fully adjusting for all evaluated confounders, these odds were attenuated but remained significant (Table 4, Model 3). For both lifetime diagnosed depression and anxiety, after fully adjusting for all evaluated confounders, the estimated odds of being in the 1-5 teeth removed or 6-31 teeth removed categories versus 0 teeth removed category were attenuated but remained significant (Table 4, Model 3).

We also used generalized multinomial logistic regression analysis to obtain predicted marginals and APRs for each level of tooth loss (i.e. 0, 1-5, 6-31 and all) for depression and anxiety. After 
Table 1. Characteristics of the study populationa , Behavioral Risk Factor Surveillance System 2008

\begin{tabular}{|c|c|c|c|}
\hline Characteristic & $n$ & $N$ & $\%$ \\
\hline \multicolumn{4}{|l|}{ Age (years) } \\
\hline $18-34$ & 9988 & 15068245 & 27.5 \\
\hline $35-44$ & 12698 & 11989760 & 21.9 \\
\hline $45-54$ & 17637 & 10924402 & 20.0 \\
\hline $55-64$ & 17849 & 8035916 & 14.7 \\
\hline $65-74$ & 12664 & 4700201 & 8.6 \\
\hline$\geq 75$ & 9650 & 3993087 & 7.3 \\
\hline \multicolumn{4}{|l|}{ Sex } \\
\hline Male & 30599 & 26447083 & 48.3 \\
\hline Female & 49877 & 28264529 & 51.7 \\
\hline \multicolumn{4}{|l|}{ Race/ethnicity } \\
\hline White, non-Hispanic & 65787 & 42192944 & 77.1 \\
\hline Black, non-Hispanic & 4550 & 4516360 & 8.3 \\
\hline Hispanic & 4208 & 4783203 & 8.7 \\
\hline Other, non-Hispanic ${ }^{\mathrm{b}}$ & 5941 & 3219104 & 5.9 \\
\hline \multicolumn{4}{|l|}{ Education } \\
\hline$<$ High school & 6091 & 4289949 & 7.8 \\
\hline High school & 22719 & 15166117 & 27.7 \\
\hline Some college & 22246 & 14702957 & 26.9 \\
\hline College graduate & 29430 & 20552588 & 37.6 \\
\hline \multicolumn{4}{|l|}{ Marital status } \\
\hline Married & 46759 & 33879698 & 61.9 \\
\hline Divorced/Separated & 12778 & 5710716 & 10.4 \\
\hline Widowed & 9631 & 3046085 & 5.6 \\
\hline Never married/unmarried couple & 11318 & 12075113 & 22.1 \\
\hline \multicolumn{4}{|l|}{ Employment } \\
\hline Employed & 45367 & 34521678 & 63.1 \\
\hline Unemployed & 3074 & 3018903 & 5.5 \\
\hline Retired & 20309 & 8298897 & 15.2 \\
\hline Homemaker/student & 7470 & 6599428 & 12.1 \\
\hline Unable to work & 4266 & 2272706 & 4.2 \\
\hline \multicolumn{4}{|l|}{ Smoking status } \\
\hline Current smoker & 12805 & 9703948 & 17.8 \\
\hline Former smoker & 24079 & 14113765 & 25.9 \\
\hline Never smoker & 43351 & 30713837 & 56.3 \\
\hline \multicolumn{4}{|l|}{ Alcohol consumption } \\
\hline Heavy & 4147 & 2964919 & 5.5 \\
\hline Moderate & 37033 & 27475950 & 51.0 \\
\hline None & 38134 & 23396808 & 43.5 \\
\hline \multicolumn{4}{|l|}{ Body mass index $\left(\mathrm{kg} / \mathrm{m}^{2}\right)$} \\
\hline$<18.5$ & 1308 & 1009618 & 1.9 \\
\hline 18.5 to $<25.0$ & 27978 & 19579311 & 36.9 \\
\hline 25.0 to $<30.0$ & 28080 & 18911753 & 35.7 \\
\hline$\geq 30.0$ & 20413 & 13520469 & 25.5 \\
\hline \multicolumn{4}{|l|}{ Ever diagnosis of chronic disease } \\
\hline Angina pectoris & 4520 & 2281684 & 4.2 \\
\hline Myocardial infarction & 4365 & 2122331 & 3.9 \\
\hline Stroke & 2808 & 1302178 & 2.4 \\
\hline Diabetes & 8497 & 4383255 & 8.0 \\
\hline Asthma & 10529 & 7380831 & 13.5 \\
\hline Use assistive technology & 7186 & 3557790 & 6.5 \\
\hline \multicolumn{4}{|l|}{ Social support } \\
\hline Always or usually & 65271 & 44350377 & 81.8 \\
\hline Sometimes & 8597 & 6107455 & 11.3 \\
\hline Rarely or never & 5807 & 3727542 & 6.9 \\
\hline
\end{tabular}

$n$, unweighted sample size; $N$, population estimate; $\%$, weighted percentage.

aggregate of 16 states: Arizona, Colorado, Hawaii, Idaho, Illinois, Kansas, Louisiana, Maine, Massachusetts, Mississippi, Nebraska, New York, North Dakota, Ohio, Vermont, and Washington.

bother, non-Hispanic includes Asian, non-Hispanics; American Indian or Alaska Native, non-Hispanics; and Native Hawaiian or other Pacific Islander, non-Hispanics. 
Okoro et al.
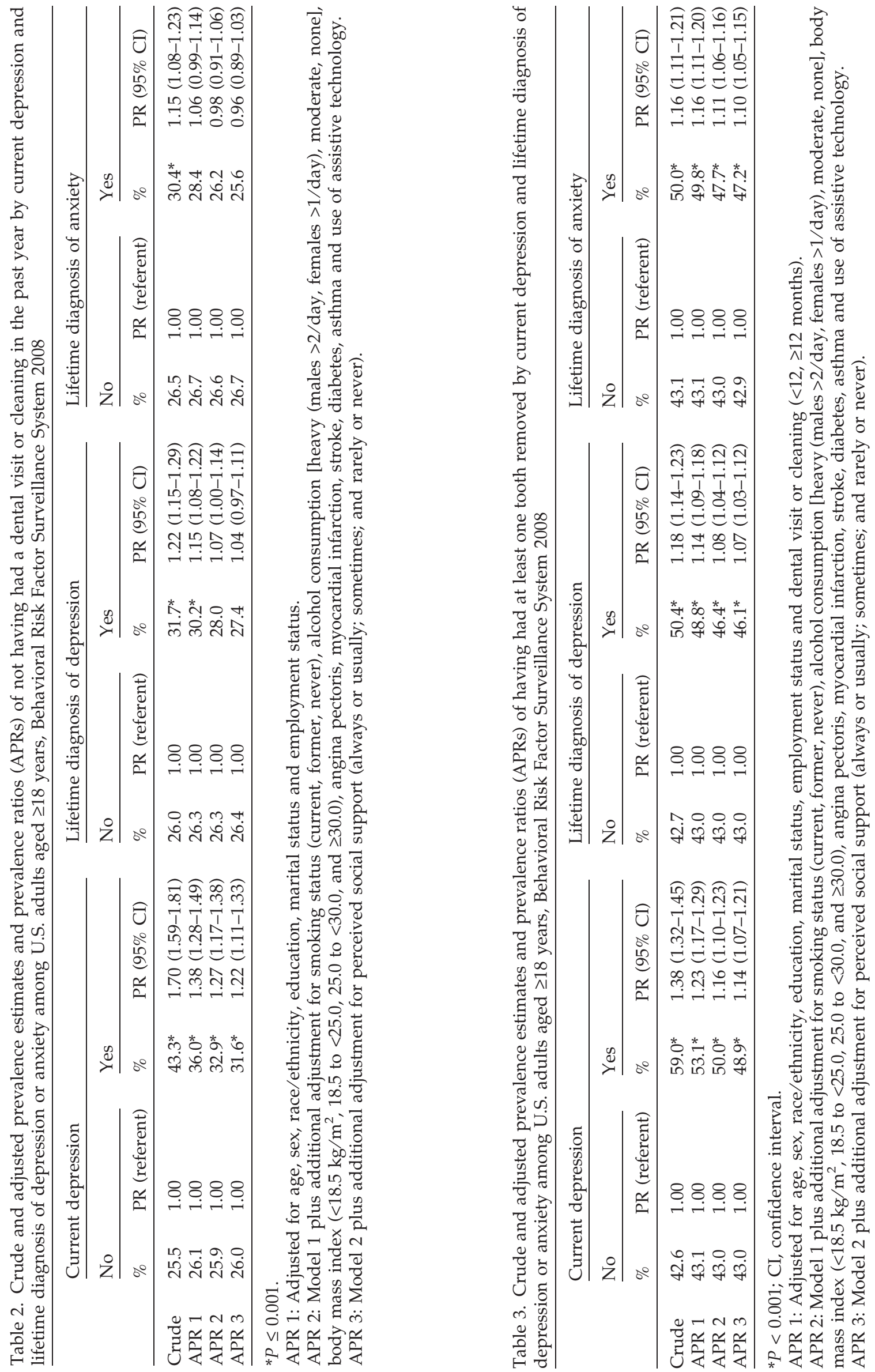
Table 4. Crude and adjusted odds ratios (AORs) between current depression and lifetime diagnosis of depression or anxiety and level of tooth loss among U.S. adults aged $\geq 18$ years, Behavioral Risk Factor Surveillance System, 2008

\begin{tabular}{|c|c|c|c|}
\hline & $\begin{array}{l}\text { Current } \\
\text { depression }^{\mathrm{a}}\end{array}$ & $\begin{array}{l}\text { Lifetime diagnosis } \\
\text { of depression }^{b}\end{array}$ & $\begin{array}{l}\text { Lifetime diagnosis } \\
\text { of anxiety }^{c}\end{array}$ \\
\hline \multicolumn{4}{|c|}{$1-5$ teeth versus 0 teeth removed } \\
\hline Crude OR $(95 \%$ CI) & $1.58(1.40-1.80)$ & $1.24(1.14-1.36)$ & $1.25(1.13-1.38)$ \\
\hline AOR $1(95 \%$ CI $)$ & $1.65(1.43-1.91)$ & $1.27(1.15-1.40)$ & $1.37(1.22-1.53)$ \\
\hline AOR $2(95 \% \mathrm{CI})$ & $1.44(1.23-1.69)$ & $1.16(1.04-1.28)$ & $1.26(1.12-1.42)$ \\
\hline AOR $3(95 \%$ CI $)$ & $1.35(1.14-1.59)$ & $1.13(1.02-1.26)$ & $1.23(1.09-1.39)$ \\
\hline \multicolumn{4}{|c|}{$6-31$ teeth versus 0 teeth removed } \\
\hline Crude OR $(95 \%$ CI) & $2.86(2.48-3.29)$ & $1.75(1.58-1.95)$ & $1.54(1.35-1.75)$ \\
\hline AOR $1(95 \%$ CI $)$ & $2.89(2.43-3.44)$ & $1.67(1.47-1.89)$ & $1.64(1.41-1.90)$ \\
\hline AOR $2(95 \%$ CI $)$ & $2.04(1.69-2.45)$ & $1.33(1.16-1.53)$ & $1.32(1.12-1.56)$ \\
\hline AOR $3(95 \%$ CI $)$ & $1.83(1.51-2.22)$ & $1.27(1.10-1.47)$ & $1.27(1.07-1.50)$ \\
\hline \multicolumn{4}{|c|}{ All versus 0 teeth removed } \\
\hline Crude OR (95\% CI) & $2.42(2.03-2.88)$ & $1.40(1.22-1.61)$ & $1.37(1.17-1.60)$ \\
\hline AOR $1(95 \%$ CI $)$ & $2.15(1.70-2.72)$ & $1.26(1.06-1.50)$ & $1.49(1.22-1.82)$ \\
\hline AOR $2(95 \% \mathrm{CI})$ & $1.58(1.23-2.03)$ & $0.96(0.79-1.16)$ & $1.18(0.95-1.47)$ \\
\hline AOR $3(95 \%$ CI $)$ & $1.44(1.11-1.86)$ & $0.93(0.76-1.13)$ & $1.14(0.91-1.43)$ \\
\hline
\end{tabular}

OR, odds ratio; $\mathrm{CI}$, confidence interval.

AOR 1: Adjusted for age, race/ethnicity, marital status, employment status and dental visit or cleaning $(<12$, $\geq 12$ months).

AOR 2: Model 1 plus additional adjustment for smoking status (current, former, never), alcohol consumption [heavy (males $>2$ /day, females $>1 /$ day), moderate, none], body mass index $\left(<18.5 \mathrm{~kg} / \mathrm{m}^{2}, 18.5\right.$ to $<25.0,25.0$ to $<30.0$, and $\geq 30.0$ ), angina pectoris, myocardial infarction, stroke, diabetes, asthma and use of assistive technology.

AOR 3: Model 2 plus additional adjustment for perceived social support (always or usually; sometimes; and rarely or never).

${ }^{a}$ Comparing adults with 0 teeth removed without current depression to each tooth loss category (1-5, 6-31 and all) among those with current depression.

${ }^{\mathrm{b}}$ Comparing adults with 0 teeth removed without a lifetime diagnosis of depression to each tooth loss category (1-5, 6-31 and all) among those with a lifetime diagnosis of depression.

${ }^{\mathrm{c}}$ Comparing adults with 0 teeth removed without a lifetime diagnosis of anxiety to each tooth loss category (1-5, 6-31 and all) among those with a lifetime diagnosis of anxiety.

adjusting for sociodemographic characteristics and use of oral health services, adults with each of these disorders were significantly more likely to have 1-5 teeth removed and 6-31 teeth removed, and significantly less likely to have 0 teeth removed, compared to those without each of these disorders (data available upon request). After fully adjusting for all evaluated confounders, these associations attenuated but remained significant, except for 1-5 teeth removed [30.8\% versus $29.1 \%(P=0.08)$; APR $=1.06,95 \% \mathrm{CI}=0.99-1.12]$ among adults with lifetime diagnosed depression and 6-31 teeth removed $[10.5 \%$ versus $9.5 \%(P=0.11) ; \mathrm{APR}=$ 1.10, 95\% CI $=0.98-1.23]$ among adults with lifetime diagnosed anxiety.

\section{Discussion}

This study, to our knowledge, is the first to investigate the associations of depression and anxiety with the use of oral health services and tooth loss in a large sample of U.S. community-dwelling adults.
Our results suggest that disparities in the prevalence of use of oral health services and tooth loss exist among persons with depression and anxiety. The prevalence of nonuse of oral health services in the past year was significantly higher among adults with current depression than those without this disorder. In addition, adults without these mental health disorders had a significantly higher prevalence of not having any teeth removed because of tooth decay or gum disease.

Adults with current depression were less likely to have used the services of a dental health professional in the past year compared to those without this disorder, even after adjustment for several confounding variables. Whereas, among adults with or without lifetime diagnosed depression and anxiety, there was no difference in use of dental services after adjustment for confounding variables. These differing findings may reflect the oral health behavioural consequences that occur among adults with current depressive symptoms who have not yet been screened for clinical depression, or, if diagnosed, remain untreated or medically noncompliant $(15,16$, 
$27,42)$. Indeed, many of the depressive symptoms identified with the BRFSS PHQ-8 (Online Appendix) may adversely affect adults' oral health behaviours, such as lack of motivation, feelings of worthlessness and fatigue $(36,37)$. Conversely, adults with lifetime diagnosed depression or anxiety may have received treatment for these disorders and, thus, be better equipped and supported to manage their oral healthcare needs. Further research is needed to elucidate the role mental health treatment and disease management plays in the associations among depression and anxiety, use of oral health services and periodontal health.

The results of this study are consistent with findings of previous studies that linked depressive disorders to a decreased frequency of oral health check-ups and an increased risk of periodontal disease and/or tooth loss $(15,19,20)$. For example, Genco et al. (19) found that, in a cross-sectional study of 25- to 74-year-old persons in Erie County, New York, depression was associated with greater levels of periodontal disease. Monteiro da Silva et al. (20) reported that both depression and loneliness were associated with adult onset of rapidly progressive periodontitis. Anttila et al. (15) reported that, in a Northern Finland cohort of persons born in 1966, depressive symptoms were associated both with a lower frequency of tooth brushing and with dental checkups.

Research has been inconsistent regarding the association between dental health behaviours and lifetime diagnosed anxiety. Anttila et al. (15) found that anxiety symptoms were significantly associated with lower tooth brushing frequency and self-perceived need of dental treatment but were not associated with frequency of dental visits. In addition, studies have reported an association between dental anxiety - a different anxiety disorder, although associated with general anxiety $(43,44)$ - and poor oral health and avoidance of oral health services (45-47). However, we were unable to explore the impact of dental anxiety on the association between lifetime diagnosed anxiety and use of oral health services in this study.

Our study is subject to several limitations. First, all data including oral health services, tooth loss, mental health disorders and confounders are selfreported. Thus, these data are subject to recall and social desirability biases and have not been validated. Second, although we have adjusted for several confounders in our analyses, we were unable to examine other factors associated with use of oral health services or tooth loss, such as dental insurance, dental caries, periodontal disease, daily hygiene routines, community water fluoridation, dentures or antidepressant medications. Third, non-Hispanic minorities, as well as persons aged 65 years or older, with less than a college education, widowed, retired and unable to work, were less likely to be included in the analysis. As many of these demographic characteristics are associated with the nonuse of oral health services, tooth loss and depression and anxiety, the effect on our findings is not known but, likely, resulted in more conservative estimates. Fourth, our study was cross-sectional. Thus, we cannot infer causality. In fact, the relationship between mental health disorders and the use of oral health services and tooth loss may be bidirectional. Mental health alone may affect oral health, physical health, health behaviours, self-management of disease, medical compliance, social interactions and quality of life (1, 48). Coexisting with poor oral health or other chronic conditions, mental health disorders contribute to severity and progression of disease and poorer outcomes (49). In addition, the use of antidepressant medications among people with depression or other mental illness may contribute to oral health disease, as increased lactobacillus counts, xerostomia, dysgeusia and bruxism are common side effects of psychotropic medication $(15,24-26)$. Conversely, persons with infrequent dental care and/or tooth loss may have a lower socioeconomic status, have lower self-esteem, have inadequate social support, lack access to oral health services, practice other health-compromising behaviours or have other health conditions that require greater resources and management. These factors may lead to depression, and compounded, contribute to the severity of depression as well.

In the United States, mental health is on the public health agenda as an integral component of health (1). In recognition of the intertwined relationship of physical health, mental health and social well-being, oral health must not be forgotten. Indeed, it is an essential component of overall health and wellbeing $(48,49)$. Our findings underscore an association between depression and anxiety and the use of oral health services and tooth loss. These findings have even stronger implications because first onset for many psychiatric disorders occur early in the life course (2), increasing their potential to negatively impact oral health over time. Longitudinal studies are needed to assess depression and anxiety disorders' oral health impact. 
To compound the issue of inadequate mental health treatment among persons with depression and anxiety (5), many of the psychotropic medications used to treat these disorders can increase the risk of dental disease $(15,23-26)$. In recognition of this as well as the interrelationship between mental and physical health, mental health professionals should encourage their patients to visit both primary healthcare professionals and dental healthcare professionals to obtain preventive services and medical and oral health care. Moreover, it is vital to inform persons that they should report all health conditions (both mental and physical) and prescription drug usage when providing medical history to dental healthcare professionals.

\section{Acknowledgement}

We thank the state BRFSS coordinators for their participation in data collection for this analysis and the Behavioral Surveillance Division staff for their assistance in developing the database.

\section{References}

1. Office of the Surgeon General, Center for Mental Health Services, National Institute of Mental Health. Mental health: A report of the Surgeon General. Pittsburgh, PA: US Department of Health and Human Services, US Public Health Service; 1999.

2. Kessler RC, Berglund P, Demler O, Jin R, Merikangas $\mathrm{KR}$, Walters EE. Lifetime prevalence and age-ofonset distributions of DSM-IV disorders in the National Comorbidity Survey Replication. Arch Gen Psychiatry 2005;62:593-602.

3. Kessler RC, Chiu WT, Demler O, Merikangas KR, Walters EE. Prevalence, severity, and comorbidity of 12-month DSM-IV disorders in the National Comorbidity Survey Replication. Arch Gen Psychiatry 2005;62:617-27.

4. United States President's New Freedom Commission on Mental Health. Achieving the promise: Transforming mental health care in America: Final report. Rockville, MD: President's New Freedom Commission on Mental Health; 2003.

5. Bijl RV, de Graaf R, Hiripi E, Kessler RC, Kohn R, Offord DR et al. The prevalence of treated and untreated mental disorders in five countries. Health Aff (Millwood) 2003;22:122-33.

6. Strine TW, Mokdad AH, Balluz LS, Gonzalez O, Crider R, Berry JT et al. Depression and anxiety in the United States: findings from the 2006 Behavioral Risk Factor Surveillance System. Psychiatr Serv 2008;59:1383-90.

7. Zhao G, Ford ES, Dhingra S, Li C, Strine TW, Mokdad AH. Depression and anxiety among US adults: associations with body mass index. Int J Obes (Lond) 2009;33:257-66.
8. Chapman DP, Perry GS, Strine TW. The vital link between chronic disease and depressive disorders. Prev Chronic Dis 2005;2:A14.

9. Strine TW, Kroenke K, Dhingra S, Balluz LS, Gonzalez O, Berry JT et al. The associations between depression, health-related quality of life, social support, life satisfaction, and disability in communitydwelling US adults. J Nerv Ment Dis 2009;197:61-4.

10. Patten SB, Williams JV, Lavorato DH, Eliasziw M. The effect of major depression on participation in preventive health care activities. BMC Public Health 2009;9:87.

11. Stecker T, Fortney JC, Prajapati S. How depression influences the receipt of primary care services among women: a propensity score analysis. J Womens Health (Larchmt) 2007;16:198-205.

12. Pearson WS, Dhingra SS, Strine TW, Liang YW, Berry JT, Mokdad AH. Relationships between serious psychological distress and the use of health services in the United States: findings from the Behavioral Risk Factor Surveillance System. Int J Public Health 2009;54(Suppl 1):23-9.

13. Kaida A, Colman I, Janssen PA. Recent Pap tests among Canadian women: is depression a barrier to cervical cancer screening? J Womens Health (Larchmt) 2008;17:1175-81.

14. Pirraglia PA, Sanyal P, Singer DE, Ferris TG. Depressive symptom burden as a barrier to screening for breast and cervical cancers. J Womens Health (Larchmt) 2004;13:731-8.

15. Anttila S, Knuuttila M, Ylostalo P, Joukamaa M. Symptoms of depression and anxiety in relation to dental health behavior and self-perceived dental treatment need. Eur J Oral Sci 2006;114:109-14.

16. Anttila SS, Knuuttila ML, Sakki TK. Relationship of depressive symptoms to edentulousness, dental health, and dental health behavior. Acta Odontol Scand 2001;59:406-12.

17. Marques-Vidal P, Milagre V. Are oral health status and care associated with anxiety and depression? A study of Portuguese health science students. J Public Health Dent 2006;66:64-6.

18. Rosania AE, Low KG, McCormick CM, Rosania DA. Stress, depression, cortisol, and periodontal disease. J Periodontol 2009;80:260-6.

19. Genco RJ, Ho AW, Grossi SG, Dunford RG, Tedesco LA. Relationship of stress, distress and inadequate coping behaviors to periodontal disease. J Periodontol 1999;70:711-23.

20. Monteiro da Silva AM, Oakley DA, Newman HN, Nohl FS, Lloyd HM. Psychosocial factors and adult onset rapidly progressive periodontitis. J Clin Periodontol 1996;23:789-94.

21. Ylöstalo P, Ek E, Knuuttila M. Coping and optimism in relation to dental health behaviour-a study among Finnish young adults. Eur J Oral Sci 2003;111:477-82.

22. Drake CW, Hunt RJ, Koch GG. Three-year tooth loss among black and white older adults in North Carolina. J Dent Res 1995;74:675-80.

23. Anttila SS, Knuuttila ML, Sakki TK. Depressive symptoms favor abundant growth of salivary lactobacilli. Psychosom Med 1999;61:508-12.

24. D'Mello DA. Are your patients depressed? Implications for dental practice. J Mich Dent Assoc 2003;85:26-32. 
25. Hunter KD, Wilson WS. The effects of antidepressant drugs on salivary flow and content of sodium and potassium ions in human parotid saliva. Arch Oral Biol 1995;40:983-9.

26. Peeters FP, deVries MW, Vissink A. Risks for oral health with the use of antidepressants. Gen Hosp Psychiatry 1998;20:150-4.

27. Dumitrescu AL. Psychological perspectives on the pathogenesis of periodontal disease. Rom J Intern Med 2006;44:241-60.

28. Holtzman D. The Behavioral Risk Factor Surveillance System. In: Blumenthal DS, DiClemente RJ editors. Community-based health research: Issues and Methods. New York, NY: Springer Publishing Company, Inc; 2004; 115-31.

29. Mokdad AH, Stroup DF, Giles WH. Public Health Surveillance for Behavioral Risk Factors in a Changing Environment. Recommendations From the Behavioral Risk Factor Surveillance Team. MMWR Recomm Rep 2003;52(RR-9):1-12.

30. Centers for Disease Control and Prevention. Behavioral Risk Factor Surveillance System Operational and User's Guide. Version 3.0. 2006. Available at: http:/ /ftp.cdc.gov/pub/Data/BRFSS/userguide.pdf [last accessed 3 May 2011].

31. Centers for Disease Control and Prevention. 2008 Behavioral Risk Factor Surveillance System Summary Data Quality Report. Version 1. 2011. Available at: ftp://ftp.cdc.gov/pub/Data/Brfss/2008_Summary_Data_Quality_Report.pdf [last accessed 3 May 2011].

32. Blumberg SJ, Luke JV. Wireless substitution: early release of estimates from the National Health Interview Survey, July-December 2008. Hyattsville, MD: US Department of Health and Human Services, Centers for Disease Control and Prevention, National Center for Health Statistics; 2009.

33. Lee S, Brick JM, Brown ER, Grant D. Growing cellphone population and noncoverage bias in traditional random digit dial telephone health surveys. Health Serv Res 2010;45:1121-39.

34. Nelson DE, Holtzman D, Bolen J, Stanwyck CA, Mack KA. Reliability and validity of measures from the Behavioral Risk Factor Surveillance System (BRFSS). Soz Praventivmed 2001;46(Suppl 1):S3-42.

35. Nelson DE, Powell-Griner E, Town M, Kovar MG. A comparison of national estimates from the National Health Interview Survey and the Behavioral Risk Factor Surveillance System. Am J Public Health 2003;93:1335-41.

36. Kroenke K, Spitzer RL. The PHQ-9: a new depression diagnostic and severity measure. Psychiatr Ann 2002;32:509-15.

37. Kroenke K, Spitzer RL, Williams JB. The PHQ-9: validity of a brief depression severity measure. J Gen Intern Med 2001;16:606-13.

38. American Psychiatric Association. Diagnostic and statistical manual - text revision (DSM-IV-TR, 2000), 4th edn. Washington, DC: American Psychiatric Publishing, Inc.; 2000.
39. US Department of Health and Human Services, Department of Agriculture, Dietary Guidelines Advisory Committee. Alcoholic beverages. Dietary guidelines for Americans, 2005, 6th edn. Washington, DC: US Government Printing Office; 2005; 43-6.

40. SAS Institute Inc. SAS for Windows. Release 9.2 ed. Cary, NC: SAS Institute; 2008.

41. Research Triangle Institute. SUDAAN user's manual. Release 10.0 ed. Research Triangle Park, NC: Research Triangle Institute; 2008.

42. Kurer JR, Watts TL, Weinman J, Gower DB. Psychological mood of regular dental attenders in relation to oral hygiene behaviour and gingival health. J Clin Periodontol 1995;22:52-5.

43. Hakeberg M, Hagglin C, Berggren U, Carlsson SG. Structural relationships of dental anxiety, mood, and general anxiety. Acta Odontol Scand 2001;59:99-103.

44. Lago-Méndez L, Diniz-Freitas M, Senra-Rivera C, Seoane-Pesqueira G, Gándara-Rey JM, Garcia-Garcia A. Dental anxiety before removal of a third molar and association with general trait anxiety. J Oral Maxillofac Surg 2006;64:1404-8.

45. Schuller AA, Willumsen T, Holst D. Are there differences in oral health and oral health behavior between individuals with high and low dental fear? Community Dent Oral Epidemiol 2003;31:116-21.

46. Hagglin C, Hakeberg M, Ahlqwist M, Sullivan M, Berggren U. Factors associated with dental anxiety and attendance in middle-aged and elderly women. Community Dent Oral Epidemiol 2000;28:451-60.

47. Sohn W, Ismail AI. Regular dental visits and dental anxiety in an adult dentate population. J Am Dent Assoc 2005; 136:58-66; quiz 90-1.

48. National Institutes of Health, National Institute of Dental and Craniofacial Research. A national call to action to promote oral health: a public-private partnership under the leadership of the Office of the Surgeon General. Rockville, MD: US Department of Health and Human Services, US Public Health Service, Centers for Disease Control and Prevention, National Institutes of Health; 2003.

49. US Public Health Service. Office of the Surgeon General. Oral health in America: a report of the Surgeon General. Rockville, MD: US Department of Health and Human Services, US Public Health Service; 2000.

\section{Supporting Information}

Additional Supporting Information may be found in the online version of this article:

Appendix S1. BRFSS Patient Health Questionnaire 8 (PHQ-8)

Please note: Wiley-Blackwell are not responsible for the content or functionality of any supporting materials supplied by the authors. Any queries (other than missing material) should be directed to the corresponding author for the article. 


\section{Appendix S1.}

BRFSS Patient Health Questionnaire 8 (PHQ-8)

Now, I am going to ask you some questions about your mood. When answering these questions, please think about how many days each of the following has occurred in the past 2 weeks.

Over the last 2 weeks, how many days have you...

...had little interest or pleasure in doing things?

...felt down, depressed or hopeless?

...had trouble falling asleep or staying asleep or sleeping too much?

...felt tired or had little energy?

...had a poor appetite or eaten too much?

...felt bad about yourself or that you were a failure or had let yourself or your family down?

...had trouble concentrating on things, such as reading the newspaper or watching the TV?

...moved or spoken so slowly that other people could have noticed? $\underline{\text { Or the }}$ opposite - being so fidgety or restless that you were moving around a lot more than usual?

Response options: ___ $=0-14$ days, $88=$ None, $77=$ Don't know/Not sure, $99=$ Refused 